\title{
ESTRANXEIRAS EN PEL E PATRIA: UNHA ANÁLISE DA DISOCIACIÓN ROSALIANA NAS PRODUCIÓNS DE XENERO CONTEMPORÁNEAS
}

Rosanna Moreda Carrizo

Centro Interdisciplinario de Investigacións

Feministas e de Estudos do Xénero (CIFEX)

Universidade de Santiago de Compostela

doi:10.17075/rcsxxi.2014.059 

Focalizando o estudo na necesidade de afianzamento e presenza das mulleres, coa finalidade de levar a cabo propostas de cambio ante ameazas de múltiples crises onde estas son especialmente vulnerables, o eixe central da análise será o concepto en auxe de identidades fluidas e as súas consecuencias en saberes e accionares. Entendemos que a tríade xeografía-fronteira-espazo é un punto de arranque crucial no proceso paulatino de disociación corpo-mente, pero non o único.

Dito doutro modo: Rosalía de Castro no poema «Estranxeira na súa patria» adiántase ao concepto de xeografía como estado físico evidenciador do conglomerado identitario e nacional, deixando entrever subxectividades máis metafísicas indisociables do xénero. Por outro lado, neste poema relatado, deixa entrever tamén unha crítica á fronteira como ente creado «dende fóra» e que novamente tende a crear as fortes dicotomías: estranxeiras/nativos - mulleres/homes, entre outras, que continúan perdurando ata hoxe. En canto ao espazo, a poeta novamente utiliza esta dimensión nun sentido crítico, cuestionando a verdadeira existencia deste espazo nun mundo construído dende as marxes de ser muller e estranxeira. Neste sentido, advertimos que o espazo se volve obxecto quimérico e focalizador central do desexo. Dende este xerme, chegamos a outros, que son precisamente os que imperan na actualidade: reafirmación do «eu», transformación do íntimo en público, apropiación definitoria do "propio» corpo..., procesos todos fortemente enlazados co traballo conxunto pola visibilidade das mulleres.

Estas son as ideas básicas propostas para un estudo onde se conxugan a análise político-literaria coa filosofía, sendo estas análises motores que aceleran unhas coordenadas de actuación que entendemos que serán, sen dúbida, beneficiosas dende unha perspectiva de igualdade de xénero.

Entón, considerando este punto de partida, poderiamos establecer un comezo, analizando o concepto de estranxeiría dende unha óptica xeográfica e actual, e tomando como referencia o xénero, de modo que as dicotomías, barreiras e separacións que o mesmo concepto encerra dende un plano xeral se continúan mantendo e, quizais con máis entusiasmo, cando incluímos o xénero. Esta será a premisa para incorrer nas implicacións de ser muller e estranxeira máis alá do sentido 
xeográfico, non negando esta perspectiva nin moito menos, senón incluíndoa como fundamental nun corpus de discriminación máis subxectivo e propio do século xxI. A estranxeiría e a acepción de tal «exclusión» de feito polas propias persoas obxecto desta evidéncianse xa na división clara de xéneros no espazo público (McDowell 1983: 59-72).

$\mathrm{O}$ poema de Rosalía de Castro que a continuación intentamos abordar, «Estranxeira na súa patria» (Castro 1981: 51), correspondente ao libro segundo: "¡Do íntimo!», de Follas novas, reflicte a segregación a todas bandas da que continúan sendo obxecto as mulleres aínda na actualidade. Novamente, a calidade visionaria da súa obra volve facerse eco nestas cinco estrofas, onde a autora pretende transcender o concepto da xeografía como delimitador dunha presenza, dunha visibilidade afogada. Xa dende o comezo do poema, apreciamos a escuridade e a angustia dun discurso que, aínda que se refire formalmente ao singular, se dirixe ou, de forma máis atinada, representa a un plural, neste caso o colectivo de mulleres marxinadas, esquecidas, invisibilizadas. $\mathrm{O}$ verso que aparece a seguir corrobora o silencio e tristura configurados nun ela explícito e elas subxacente:

\footnotetext{
Na xa vella baranda

entapizada de hedras e de lirios

foise a sentar calada e tristemente

frente do tempro antiguo.
}

A característica ambivalencia da autora entre o discurso íntimo e público, entre a singularidade dun «eu» e un plural «nós», así como o discorrer político-poético están moi presentes neste poema. Isto é evidente se nos detemos nas imaxes relatadas, que, debido á forte asociación construída ao longo do tempo ao redor da opresión feminina, deviñeron arquetipos no sentido agora máis plenamente junguiano. Un exemplo destes arquetipos retóricos moi representativo sería o silencio feminino xa comentado, asociado á tristura de que se fala no terceiro verso. Estes necesarios arquetipos, por outro lado, ofrecen a posibilidade xa coñecida de xeneralización, crucial en todos os cambios de paradigma, de perspectiva, pois ao estar tan presente no imaxinario, neste caso feminino, funcionan a xeito de engrenaxe entre o particular e o xeral. De aí a importancia da correlación do "eu» íntimo e o «nós» plural a unha escala xa de implicacións políticas. Intentaremos expoñer, 
polo tanto, unha interpretación que parte de elementos puramente estilísticos, coa intención de extrapolar os ditos semas contextuados en verso a ámbitos non poéticos e de grande alcance a nivel de cambio social. Esta extrapolación de campos, completamente atemporal, e de necesaria fixación en grupos (mulleres) e subgrupos de minorías mulleres conceptualizadas baixo esta categoría (pobres, marxinais, aldeás...), consideramos que é un dos méritos máis significativos da poeta.

Como xa bosquexamos, a inauguración do poema que aquí se presenta parte cunha estrofa onde, dende esta base estilística á que fixemos referencia, aparecen dous elementos do cosmos vexetal, onde se presentan respectivamente outros dous dos puntos neurálxicos claves na súa obra: a fronteira, xa non xeográfica, que leva ao estandarte nacionalista á procura de autoafirmación, senón humana. Fronteira humana que reduce o espazo feminino e que se traduce en incomprensión, soidade e angustia existencial, este sería o segundo punto neurálxico.

Non é fortuíto, polo tanto, seguindo con esta lińa, que apareza a antítese de dous conxuntos botánicos (Orobitg 1999: 946) para representar un complexo emocional que conforma o sustento da súa filosofía. Segundo esta autora:

Los vegetales relacionados con el yo poético o sus dobles (la yedra y los vegetales marchitos, emblemas de duelo y de flaqueza) y los vegetales asociados a la dama, como el laurel (del que me ocuparé más adelante) y una serie de vegetales nobles y de flores esplendorosas, brillantes, de tallo alto y colores vivos, asociados al campo semántico de la luz y de la elevación. La dama queda frecuentemente asociada, de manera tópica, al lirio y a la rosa.

Aínda que esta autora basee esta analítica en parte da obra do escritor sevillano do século XVII Francisco de la Torre, detense en elementos da poesía aurisecular cuxa simboloxía ten un trazado o suficientemente xeral para perdurar ata a actualidade. Isto é evidente na asociación do sema flor «rosa» e as construcións consecuentes asociadas a cosmoloxías femininas.

Polo tanto, no devir do relatado por Rosalía, a yedra e o lirio conforman un par antagónico máis, onde o sentimento de exclusión e de carencia que na poeta é magnificado coa finalidade de resaltar a denuncia social se simboliza nesta planta, a yedra, planta por outro lado discreta, taciturna, sen o esplendor e luminosidade que poderían simbolizar moitas flores ou outro tipo de plantas. 
Esta dinámica de pares en continua loita é evidente ao longo do poema, tomando a abstracción fronteira un significado metafísico e transversalmente fantástico, onírico, opoñendo a vida e a morte máis aló do sentido corporal, obxectivo, senón espiritual. A potente carga desta idea exprésaa, non obstante, con ironía serena e sutileza medida no segundo verso da segunda estrofa:

Interminable procesión de mortos

uns en corpo no-máis, outros no esprito,

veu pouco a pouco a aparecer na altura

do direito camińo,

que monótono e branco relumbraba

tal como un lenzo nun herbal tendido.

O corpo morto físico «no-máis» dende este prisma entendemos que non ten a importancia «ética/social» do corpo morto espiritual. Neste tramo, concibimos a densa poetolóxica de Rosalía como unha ondada perpetua onde se confrontan os outros, (cousificados nunha morte que, aínda que asumida nunha antiquísima tradición bucólica non estrañada, non deixa de ser tétrica) e o propio espazo feminino (cousificado tamén baixo outro tipo de distanciamento: o distanciamento do propio corpo obrigado dende o establishment patriarcal). Ou, noutras palabras, concibimos a forte necesidade performativa das «suxetas» para utilizaren o recurso dos ámbitos fronteirizos para o afianzamento de modos discursivos de autorrepresentación (Palma 2008).

Advírtase que, a medida que o poema fermenta, as figuras necrolóxicas tamén o fan, pero dun xeito asumido e integrado, como selo característico da literatura pagá da que Rosalía é herdeira. Pero, neste caso, a fantasmática ${ }^{1}$ non é fin, senón ferramenta que dá forza á súa técnica dicotómica que evidencie a total ausencia, carencia, voz, do seu espazo «eu»/«ela» muller:

Contemprou cal pasaban e pasaban

correndo hacia o infinito,

sin que ó fixaren nela

1 No dobre sentido (estético) de espectral e de representación relacionada co temor. 
os ollos apagados e afundidos

deran siñal nin moestra

de habela nalgún tempo conocido.

Sen esquecernos que a obra desta autora se enmarca nun contexto onde non moi lonxe de terras galegas predominaba o vitorianismo, a metáfora que utiliza novamente no segundo verso desta terceira estrofa: «correndo cara ao infinito» referíndose a estes cadáveres, que, en principio, entendemos como masculinos, non é nin moito menos casual. Referímonos a que esta ausencia de voz é exemplarmente notoria nas mulleres vitorianas que loitaban por un empodeiramento (Domosh 1990), fortes predecesoras do actual, en termos máis concisos. Esta autora citada, con especial mestría, céntrase na natureza borrada das mulleres viaxeiras decimonónicas británicas e a súa consecuente necesidade de traspasar a fronteira de «outsider» para si mesmas, que é xustamente o miolo do texto aquí traballado:

Yet many women explorers were arguably better suited to deal with their ambiguous role. They were outsiders in the everyday world by virtue of their sex, and much of their energy throughout their lives had been spent dealing with that fact. The ambiguity of the role of explorer was not new to them. As women, their lives were created around that dilemma; they were certainly insiders and participants in their culture, yet they always stood outside the structures of power. Women carried that duality of identity into the field with them, and they found that such duality served them well. At home they were outsiders by virtue of their sex; in the field they were outsiders by virtue of their race (Idem, 98-99).

A investigadora céntrase nas exploradoras do século XIX, como é o caso da viaxeira e escritora Isabella Bird, para representar a posta en práctica, xa urxida naqueles tempos, de estratexias de poder e visibilización dende un activismo do xénero, logrados neste caso por medio da ficción da viaxe. Para o poema da creadora galega que aquí nos ocupa, encontramos certos elementos que, nalgún sentido, evocan a heroicidade da viaxe (Bajtín 1979), onde a persoa, no seu desdobramento de ser viaxeira, se transforma e reprega en ente que anhela ser, e presenciamos tamén a outra cara do nomadismo no seu devir en xeografías movedizas: disociación dun corpo que remata no descoñecerse a si mesmo, pois non é (re)cońecido. 
Disociación/desdobramento que, por outro lado, xorden precisamente da aventura (Morató 2001), do lanzarse a terras descońecidas e deixar o niño, a seguridade e os lazos que xorden do fogar e do cońecido. Neste sentido é no que podemos afirmar que abandonar o coñecido é abandonar o «si mesma». De aí que se suxira a idea de heroicidade da viaxe pola busca constante deste «si mesma» aínda non encontrado e aferrarse ao nomadismo como estratexia para encontrar o recońecemento dos demais para si e do si para si no cambio radical que implica toda viaxe. O risco desta acción é, polo tanto, heroica en termos bajtinianos.

De modo que a estranxeira na súa patria sofre unha marxinación dobre se nos atemos, por un lado, a esta disociación que provén do non recońecemento e que traspasa a barreira da xeografía, e, polo outro lado, unha marxinación que provén desta heroicidade da viaxe que acabamos de comentar, pero de xeito totalmente inverso: a nosa estranxeira, lonxe de gozar dos privilexios da muller aventureira (vitoriana ou non) que marcha para despois dun tempo «X» regresar, é completamente invisible aos ollos da súa xente achegada e representada, non casualmente, en corpos mortos masculinos.

É unha Rosalía sen home, soa de todos, mesmo de si mesma, estranxeira polo tanto para si mesma, e paradoxalmente autónoma, libre, nesta soidade (Blanco 1998). Non pode obviarse o feito de que esta experta lucense en estudos rosalianos, Carmen Blanco, é unha precursora da abordaxe feminista do concepto estranxeiría neste poema e noutros da poeta galega, e que destaca de forma lúcida esta ambivalencia da liberdade na soidade. Idea complexa e interesante, chea de matices mitolóxicos, que se deducen de todo o anterior.

Na penúltima estrofa, De Castro dá un paso máis na subversión da súa lírica para deixar ben claro que «a estranxeira» fixo un uso pleno da súa liberdade, aspecto escasamente frecuente nesa época, e, sobre todo, afianza, no primeiro verso desta estrofa, o exercicio do desexo autónomo, activo, moldeado, pertencente tamén ao «eu/ela» muller:

I uns eran seus amantes noutros días,

deudos eran os máis i outros amigos,

compañeiros da infancia,

sirventes e veciños. 
Aínda que de xeito discreto, séntense aquí os ecos da sexualidade feminina recuperada (Pinkola 2009: 467); a antiga sexualidade que naturalizaba as relacións amorosas nese punto esvaído onde se enlazan o sagrado e o profano. Por outro lado, a suposición de que se refire a un «outro masculino» afiánzase no «masculino xenérico» que a autora elixe e utiliza dabondo para referirse aos comentados: amantes, amigos, compañeiros de infancia, serventes e veciños respectivamente. Convén destacar, así mesmo, a presenza solapada, sutil, de acordes plenamente transgresores na poesía rosaliana, de cheo actuais e principalmente axustados aos ventos do século XxI. Elementos transgresores que se deducen a miúdo nun non detemento exhaustivo naqueles feitos que sairían do normativo para a súa época, como no exemplo que acabamos de comentar acerca de «antigos amantes», onde se fai obvia esta transgresión/subversión.

De feito, as implicacións semánticas, morais, sociais e relixiosas que xermolan mecánica e inmediatamente ante a asociación muller galega no século XIX - amantes reforza este antagonismo do que vimos falando e, por outro lado, a estrutura subversiva, adxacente e cuestionadora dos poderes e pensamentos establecidos vólvese evidente. Como evidente se volve, tamén, a forte necesidade na voz/voces do poema de «desestranxeirizarse» para sentirse parte dunha colectividade non sinalizada, nunha diferenza inimiga que a discrimina e a esencializa na súa condición de muller, xa dende a lectura que faría Gayatri Spivak sobre a necesidade de acción dende a subalternidade (Segarra 2006), xustamente para intervir e cambiar a realidade dende a posición/acción directa das persoas «afectadas», directamente dende elas. De feito, unha das maiores proezas da pensadora bengalí foi a difícil tarefa de problematizar, deconstruír o concepto de estranxeirización para loitar contra a nociva tendencia de esencializar e cousificar a diferenza, pero sen que isto menoscabe en absoluto a necesidade de ter voz propia (Spivak 2010).

Por último, como conclusión do manifesto, Rosalía fai uso da hipérbole nocturna para resaltar a indiferenza de que é obxecto, así como a desprotección á que alude case ao final: "Que sen lar nin arrimo...».

Mais pasando e pasando diante dela

fono os mortos aqueles prosiguindo

a indiferente marcha,

camińo do infinito, 
mentres cerraba a noite silenciosa

os seus loitos tristísimos

en torno da estranxeira na súa patria,

que sin lar nin arrimo,

sentada na baranda contempraba

cal brilaban os lumes fuxitivos.

É tanxible que a intención da poeta con este poema fose tamén, de xeito sempre transversal, expoñer unha problemática moi frecuente cando as xeografías eran menos escorregadizas do que son na actualidade, que están configuradas máis de forma continua e ao redor de redes (Claval 1999: 353), que a espazos inmóbiles e inconmensurables. Por este problema referímonos ás mulleres que emigraban da súa terra natal, neste caso Galicia, e que, ao cabo de moitos anos, cando decidían volver ao seu lugar de orixe, con frecuencia vilas e aldeas, eran fortemente discriminadas; o resultado deste cruel proceso era unha perda de identidade tan forte como a que se entende por estranxeiría no seu sentido estándar. Polo outro lado, isto é un problema que vai paralelo frecuentemente ás crises económicas e, polo tanto, en auxe aínda na actualidade ${ }^{2}$.

\section{CONCLUSIÓNS}

Como resultado deste bosquexo, dedúcese, en primeiro lugar, que as identidades fluidas ás que facemos referencia conforman unha sorte de saída ante as barreiras expresivas que atentan contra o traballo das mulleres. En termos simples, da identidade fría monolítica máis característica de tempos previrtuais pasamos ás identidades quentes grupais/en rede como forma máis efectiva de cambio político.

En segundo lugar, destacamos a enorme importancia das repercusións dende o punto de vista dos estudos de xénero da tríade xeografía-fronteira-espazo como conceptos metonímicos que traspasan o meramente físico para dirixirse aos impedimentos que obstaculizan unha verdadeira presenza feminina a todo nivel. Impe-

2 Aínda que novamente non afondaremos neste problema, este fenómeno negativo para suxeitos e suxeitas de «estranxeirizar tamén os/as non estranxeiros/as» é moi frecuente nos países de orixe das correntes migratorias que retornan e son «culpabilizadas» por marchar. 
dimentos que se representan na fronteira imposta ante a xeografía e o espazo acoutados.

Vimos tamén que a reafirmación do «eu»é un equivalente poético da necesidade de acción por un «nós», sendo que na extrapolación que a poeta fai no poema como estranxeira que regresa á súa terra se fai notorio o plural ou a inferencia do particular/persoal ao xeral/grupal, traducido de forma moi práctica ao cońecido slogan de Kate Millet: o persoal é político, frase crucial que entronca, en boa medida, coa urxente e reivindicativa apropiación definitoria do "propio» corpo, procesos todos fortemente enlazados co traballo conxunto pola visibilidade das mulleres.

Finalmente, e de forma máis que nada esperanzadora e pragmática, poderían suxerirse certas perspectivas que alteren a invisibilidade en corpos e voces femininas que aínda continúan sendo latentes. Se ben é certo que a poeta galega deixou unha gran pegada como reivindicadora de liberdades que aínda estaban moi lonxe de conseguirse, mesmo en pleno século xxI, habitamos un mundo totalmente distópico en canto á conquista de dereitos se refíre. Confiemos, non obstante, en que podería enxergarse algún tipo de saída nos traballos cruzados. Con esta expresión fago referencia á obra de creadoras que escapan do seu propio marco e actuación, xustamente porque a necesidade de cambio para mellorar a realidade se sente como algo vital, non como algo que se elixa ou se impońa, senón como algo que, en ningún modo, se pode obviar.

Paradoxalmente, podemos enxergar outro camiño en terras tecnolóxicas, nas identidades conxuntas e, xustamente por iso, fluidas. Un camiño calidoscópico que depende da perspectiva tamén perde e confunde, pero camiño á fin e ao cabo, onde poidamos, por diante de todo, elixir. Espazos ceibes como as redes sociais e as bitácoras ofrecen a posibilidade de producir unha enormidade de traballos cruzados, onde imperan creacións que traspasan o campo da arte non por solidariedade só de palabra, cuestión doutras épocas, senón por obrigada subsistencia nun mundo agonizante. De Castro foi unha delas, porque non se conformou con facer poesía dentro de canons estritamente poéticos. Ela viviu os problemas da súa época dun xeito demasiado intenso para conformarse coa estática da tinta e $o$ papel, todo o contrario a producir «cantidades ingentes de poesía a través de los tiempos: amor tan profundo como los océanos, o lo que sea» (Xue 2007: 61), en irónica expresión da escritora chinesa xustamente para referirse á típica escritura 
patriarcal (e non patriarcal, pero que se axusta ao molde) de todos os tempos e lugares. Por iso Rosalía de Castro foi unha creadora basicamente política. A súa poesía foi (pre)texto, sempre, sempre adiante do texto.

E foi precisamente esta postura incómoda ante a realidade que se ofrecía aos seus ollos e o non permitir a si mesma mirar cara a outro lado nin deixarse tentar por unha entregada estética tentadora, pero de escabrosa displicencia, o que herdaron estas innumerables escritoras actuais, na súa enorme maioría anónimas, que traballan por/en rede coa esperanza de postergar un pouco máis esta, a nosa lenta pero firme agonía planetaria. 


\section{REFERENCIAS BIBLIOGRÁFICAS}

Bajtin, Mijaíl (1979): Estética de la creación verbal, Madrid, Siglo XXI.

BLAnco, Carmen (1998): «A subversión múltiple, “Estranxeira na súa patria” de Rosalía de Castro», Unión Libre, 3, 37-48.

Castro, Rosalía (1981): Follas novas, Vigo, Castrelos.

Claval, Paul (1999): La geografía cultural, Bos Aires, Eudeba.

Domosh, Mona (1991): «Toward a Feminist Historiography of Geography», Transactions of the Institute of British Geographers, 16:1, 95-104.

McDowell, Linda (1983): «Towards an understanding on the gender division of urban space», Environment and Planning D: Society and Space, 1, 59-72.

Morató, Cristina (2001): Viajeras intrépidas y aventureras, Barcelona, Plaza \& Janés.

Orobitg, Christine (2001): «La yedra en la poesía de Francisco de la Torre: simbología y autorepresentación», en Christoph Strosetzki (coord.), Actas del V Congreso Internacional de la Asociación Internacional Siglo de Oro (AISO), Münster 20-24 de julio de 1999, Iberoamericana / Vervuert Verlagsgesellschaft, 941-953.

Palma, Miriam (2008): «Porque la palabra hablada se hace carne. Corporeidad y escritura en los textos de Yoko Tawada", en Meri Torras / Noemí Acedo (eds.), Encarna(c)ciones. Teoría(s) de los cuerpos, Barcelona, UOC, 156-160.

Pinkola, Clarissa (2009): Mujeres que corren con los lobos, Barcelona, Ediciones B.

Segarra, Marta (2006): «Más allá del poscolonialismo. Contra la subalternidad», suplemento Cultura de La Vanguardia, 01/03/2006, 5. Dispoñible tamén en versión electrónica (http://hemeroteca.lavanguardia. com/preview/2006/03/01/pagina-5/46412084/pdf.html).

SpIVAK, Gayatri (2010): Crítica de la razón poscolonial. Hacia una crítica del presente evanescente, Madrid, Akal. XuE, Xinran (2007): Nacer mujer en China, las voces silenciadas, Barcelona, Planeta. 
